\title{
Historical changes in the melodic structure of Setu laments
}

The present discussion addresses the problem whether the Setu lament tunes stored at Estonian folklore archives are melodically homogeneous or whether the changes characteristic of traditional Setu songs have also affected the lament tunes. It is natural to assume that the general development of musical culture applies to all genres, but the question remains on what levels and in what elements of the system those changes are manifested. To find an answer to that the material was approached on three structural levels - form, metre and pitch - and studied by two methods of analysis. To find out the identifying features of lament tunes traditional music analysis was applied. According to this lament tunes represent a homogeneous set of melodies structured by similar rules, except in pitch, that display considerably more heterogeneity than the linguistic or metric aspects.

In order to find out the rules underlying the pitch structure of the lament tunes the pitch structures of three laments with a relatively stable metre and form were compared by the method of interactive structuring. Hitherto that method has - to a limited extent been used in economic and social sciences. With more complicated objects of research, however, like the melodies of Estonian folk songs, it is used for the first time. Interactive structuring belongs to a group of methods of mathematical structuring. In the present study it has been used for a stepwise formation of sets of scale steps used in a lament tune, or of groups of such scale steps, proceeding from their frequency of occurrence. As a result, the relations and hierarchy of the steps used in the lament are made explicit. As was proved by the analysis the lament tunes have been subject to several changes during their history of development, providing for the unique character of each of the three melodies analyzed.

\section{Introduction}

Laments are a specific genre of folklore belonging to the traditional culture of GreekCatholic Baltic Finns, incl. the Setu minority living in southeastern Estonia. Laments as part of the transition ritual (rites de passage) mostly belong to funerals and weddings. Their form, metre and rhythm have come through to our days relatively intact, whereas the melodic contour has suffered remarkable changes. The reasons lie, most likely, in the survival of Setu dialect usage whence the lament derives its metric and rhythmical properties. The principles of parallelism and alliteration still characteristic of the laments, are also rooted in verbal thinking. The pitch structure of Setu laments, however, has changed a great deal. The gradual replacement of the regular lament melody by a more liberal approach observable in the part of the leadsinger in Setu 
bridal laments will be discussed below.

Setu laments are distinguished from other folklore genres not only by their function of establishing contacts with those members of the tribe who have passed away. In addition the laments have a relatively stable musical structure, enabling the recognition of a lament without comprehending the text or seeing the performance. In Setumaa, 1980 I was told that lamenting had been heard sounding from the other end of Kosselka village. Just from a few fragments of melody overheard the people had understood that someone had passed away and the rite of passage had been commenced. But beside funeral laments, wedding laments, too, have a specific form. People remember that once the descending melody contour of bridal laments used to be recognized from afar as well, even though unlike laments for the dead that used to be sung solo, bridal laments were performed by a leadsinger and chorus alternating.

The following analysis is based on the recordings of 80 Setu bridal laments, deposited at the Estonian Folklore Archives. The material was recorded in different regions of Setumaa during the years 1937-1980.

The recordings reflect the way bridal laments were performed when the singers $(b$. 1877 - 1922) were still young, which means that we are dealing with the tradition characteristic of the first decades of the 20th century. As the laments have been recorded outside their natural performing situation not much can be inferred from this material as to what real lamenting was like. Nevertheless, the material is reliable enough to enable an analysis of lament structure. Certain limits were set by the technical quality of the recordings, which, to be eligible for our analysis, had to be good enough to enable the transcription of the notes of the leadsinger's part at least, as her melody supports the polyphony of the chorus. The polyphonic part will be left out of the analysis anyway, as the quality of the old recordings forbids to distinguish linear movement in the different parts of the polyphony of the laments.

\section{Form}

The analysis is based on the main formal unit of the lament, which is one text line together with a corresponding tune (A). One line (usually lasting 4-5 seconds) is the structural unit the varied iterations of which make up a full lament $\left(A_{1} A_{2} \ldots A_{n}\right)$. One lament may last half an hour or even longer. In the typical runic verse a line consists of two half-lines $(a+b)$.

Table 1. The form of a text line of the Estonian runic verse

$$
\text { Half-line a half-line b }
$$

Text 4+4 syllables: Mi-no mee-li ma-r'a-kõ-n

In a Setu bridal lament the first half-line (a) is always longer than the second (b), and it always contains a one-syllable word linking the line to the address word ${ }^{1}$. In the

\footnotetext{
1 Timo Leisiö has suggested the term 'trigger' for that one syllable word. The Trigger is an additional position of the line in bridal laments whitch is situated at the end of the second foot. It is an additional syllable having or having not a meaning in normal sense. But this syllable has a specific function because of which it is called a trigger. When a singer approaches the trigger she is bound to make a decision what
} 
leadsinger's part the first half-line is usually immediately followed by the second halfline. In the chorus, however, the connection is always preceded by a word addressing the person to whom the lament is dedicated.

Table 2. The form of the text line of a Setu lament verse

\begin{tabular}{|c|c|c|c|}
\hline \multirow[t]{2}{*}{ Performed text: } & Thou art & /brother/ & the berry of my hearth \\
\hline & Half-line a & /addressing formula & half-line $\mathbf{b}$ \\
\hline Leadsinger: $4+1+2+4$ syllables: & Mi-no o-lõt/sa & mee-li & $m a-r^{\prime} a-k \tilde{o}-n \tilde{o}$ \\
\hline Chorus: $4+4+1+2+4$ syllables: & Mi-no o-lôt & Ivelekenel & $m a-r^{\prime} a-k \tilde{o}-n \tilde{o}$ \\
\hline
\end{tabular}

During actual performance the singers are dividing the lines, simultaneously applying certain rules of the poetic text and some other rules imposed by the lament tune. As a result, in Setu bridal laments we get two melodic motifs $\left(\mathrm{a}^{1}\right.$ and $\left.\mathrm{a}^{2}\right)$ that shift the caesura forward, so that the text line A and the corresponding melody line A are not divided similarly.

Table 3. The form of a Setu lament melody

\begin{tabular}{|c|c|c|c|c|}
\hline & $\begin{array}{l}\operatorname{motif} \mathbf{a}^{1} \\
\text { Mi-no o-lõt sa }\end{array}$ & / Addressing refrain / & $\begin{array}{l}\text { motif } \mathbf{a}^{2} \\
\text { mee-li }\end{array}$ & $\begin{array}{l}\text { motif b } \\
m a-r^{\prime} a-k \tilde{o}-n \tilde{o}\end{array}$ \\
\hline borus. & Mi-no o-lõt & /velekene/ & sa mee-li & $m a-r^{\prime} a-k \tilde{o}-n \tilde{o}$ \\
\hline
\end{tabular}

\section{Metre}

Conventional analysis of runic texts has always been syllable-centered. Syllables have been counted, their duration and stress relationships calculated. Estonian verse theoretician Jaak Põldmäe has made a compendious statement to the effect that Estonian prosody enables one to combine the regularization of syllable duration with either that of stress variation or of number of syllables in the line, or both (Põldmäe 1978: 150152). Consequently, he has considered the runic verse as a syllabic-duration system and at the same time a system regularized by stress.

Setu bridal laments consist of lines that include, as a rule, 9 to 11 syllables. In addition, the number of stress groups and the duration of syllables are considered. Runic songs in the so-called quantitative verse are characteristic of the Estonian area in general, but usually the line has 8 syllables. In Setu laments, however, the metre depends on syllable stress and so the number of syllables in a line usually varies. In principle, the metre of Setu bridal laments corresponds to that of funeral laments, but the former is closer to songs in that it is less liable to variation (Sarv 1993). The metrics of a Setu lament rests on the metre of a rhythmic system. The stress groups of laments may contain 2-3 syllables structured according to the paeon. 
Table 4. A paeon-derived metrical scheme

$$
\text { I: +o II: +oo III: +olor/ +oo IV: +olor/ oo olor/ +ooo }
$$

Regular metre rests on isochronous stress groups consisting of groups of syllable notes. As in the Estonian language word stress regularly occurs on the first syllable, it is characteristic of the lament tune that every tone corresponding to a word-initial syllable is stressed. A considerable bulk of the words used in runic songs have two syllables, three-syllable words are less frequent. As for one-syllable words their number formally exceeds that of three-syllable ones, but in song texts the former either occur in pairs $(k a s+\tilde{o} k s)$ or are linked to a two-syllable word, usually the following one, but sometimes the preceding one ('om-mõ $+m u l$; ' $a r$ ' + min-nä). Longer words develop an additional (secondary) stress but in the runic metre it functions similarly to the main stress $(+\mathrm{O} O \mathrm{O}=+\mathrm{o}+\mathrm{o})$. Four-syllable words are rather characteristic of line

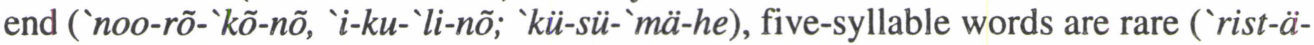
mä-'ke-ne; ‘ku-mar-da-'mi-ne; 'tar-gõm-ba-`kõ-sõst).

The length of a stress group corresponds to that of a disyllabic or a trisyllabic word. The main stress of a word concurs with the stressed tone of the lament tune, which is also the highest pitch of the stress group.

Table 5. Metrical patterns of lament lines

\begin{tabular}{|c|c|c|c|c|c|}
\hline \multicolumn{2}{|c|}{$\begin{array}{l}\text { Number of syllables } \\
\text { in a text line }\end{array}$} & \multicolumn{3}{|c|}{ Stress groups I - IV } & \multirow{2}{*}{$\begin{array}{l}\% \text { of pattern } \\
\text { occurrence } \\
\text { /syllables }\end{array}$} \\
\hline & I & II & III & IV & \\
\hline \multirow[t]{2}{*}{9} & & +00 & +0 & +0 & $15 \%$ \\
\hline & Maa-ma- & kõnõ mu & ar-ma- & kõ-nõ & $2+3+2+2$ \\
\hline \multirow[t]{2}{*}{$10 \mathrm{a}$} & +0 & +00 & +00 & +0 & $20 \%$ \\
\hline & Näi-o & sul-lõ ma & ku-mar-da & jal-ga & $2+3+3+2$ \\
\hline \multirow[t]{2}{*}{$10 \mathrm{~b}$} & $+o$ & +00 & +0 & +oo & $42 \%$ \\
\hline & Pe-rä- & mä-ne mul & om-mõ & ik-mi-ne & $2+3+2+3$ \\
\hline \multirow[t]{2}{*}{11} & & +00 & +0 & +000 & $20 \%$ \\
\hline & sul-lõ & $n a-k a \boldsymbol{m a}$ & jal-ga & ku-mar-da-ma & $2+3+2+4$ \\
\hline
\end{tabular}

\section{Rhythm}

A lament tune has a syllabic structure, which means that one pitch corresponds to one syllable. The number of notes in a lament tune corresponds to the number of syllables in the text line. The length of notes corresponds to that of syllables, as the main aim is to communicate the lament text. According to duration, the Estonian syllables are usually divided into three groups: short, long, and overlong syllables. In Setu laments the length of the vowel in a short syllable is appr. $70-100 \mathrm{~ms}$, while in a long syllable it is appr. $140-180 \mathrm{~ms}$ and in an overlong syllable it is appr. 340-380 ms. According to a laboratory measurement the difference between a leadsinger's shortest and longest syllables in an emotionally performed lament can be four- or fivefold. 
Table 6. A $3300 \mathrm{~ms}$ line of an emotionally performed lament (vowels - $1440 \mathrm{~ms}$ ).

Performed text line (Abuse of the deceitful boy)

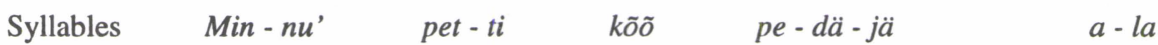

Duration of vowels

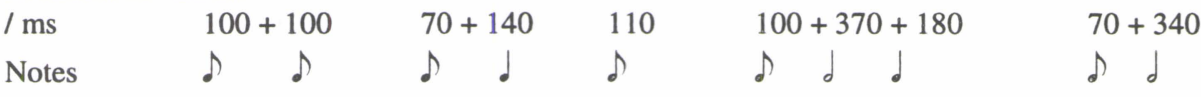

As most of the bridal laments available in Estonian archives have been recorded at the request of a folklorist outside the real context, they resemble, to a certain extent, lyrical folk songs. Notably, in folk songs tone lengths have a tendency to isochrony and the tunes of bridal laments obey this regularity. The transcribers of laments have used notes of two lengths: a lament begins with a sequence of short syllable-notes $(\supset \supset \supset \delta)$ and the part of the leadsinger ends in a long syllable-note (১). The movement of the bridal lament is more lively than that of a funeral lament $(\mathrm{MM} \quad \delta \sim 180)$.

Table 7. Schematic rhythmic patterns of lament lines

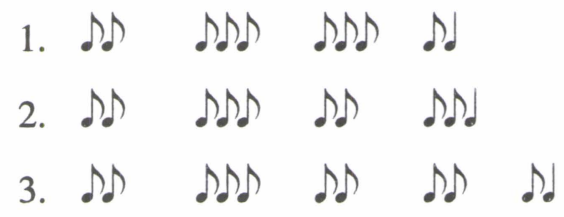

\section{Tonal structures}

Pitches and their relations belong to essential structural elements of music. Tonal material and the melodic thinking based on it can be discussed from three aspects (Lippus 1995, 86). 1. First, the pitch continuum of the whole material is divided into distinct pitches and the resulting steps are organized into melody scales. 2. Next, the tones are organized into hierarchies or tonal structures to show which pitches carry the reference function. Referential pitches enable orientation in the pitch continuum, and other intervals are stabilized in relation to them. 3. Finally, there follows an analysis of melodic syntax to show how the tonal steps and melodic patterns combine to make up the melody of a folk song.

\section{Scales and modes}

More than half of the tonal sequences (scales) of Setu bridal laments include the steps fis-g-b. Quite often the whole lament tune is based on these three referential pitches, possibly supplemented by a subquart (d) and also a subthird (es). In most cases the main referential pitch $(\mathrm{G})$ of the scale serves as the final tone, but it can also be the beginning of the next motif. The frequency of scale steps as measured on the material of 20 Setu bridal laments (536 lines, 5334 syllable-notes) helps to determine the function of the steps. The three referential pitches make up $77 \%$ of all notes of the lament tune, while the most frequent one is $\mathrm{G}$ as the main referential pitch. 
Table 8. Proportion of scale steps (\% of syllables / notes)

$\begin{array}{lllllllll}\text { Note } & \text { d } & \text { es } & \text { f } & \text { fis } & \text { g } & \text { a } & \text { bb } & \text { ces } \\ \text { \% of syllables-note } & 6,0 & 3,7 & 3,4 & 21,4 & 36,7 & 9,4 & 19,00 & 0,01\end{array}$

The main referential pitch of the lament tune is, as a rule, central to the scale. This type of musical thinking is characteristic of all Setu archaic ritual songs (Sarv 1986). In some variants the third located above the main pitch has been replaced by a second (fis-G-a), in still fewer cases it may happen that the leading tone is lowered (f-G-b).

Table 9. Maximum scale used by a lead-singer

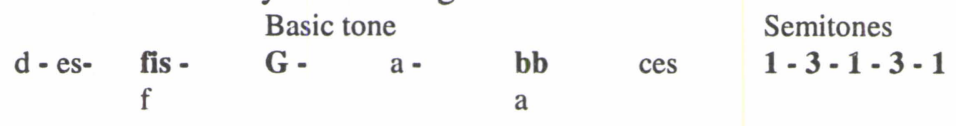

In Setu bridal laments the leadsinger's scales usually consist of 3-5 steps. 4-5-step scales, although proceeding from a triad, are as a rule extended towards the lower tetrachord. The scales are invariably semitonal, while measuring the intervals in semitones we get a 1-3-1-3-1 scale typical of Setu ritual songs (Pärtlas 1997). In certain positions of the scale one may often meet "blanks", i.e. unused pitches. Those positions occur in the upper tetrachord (between the referential pitch and the third tone) and the lower tetrachord (between the subquart and the leading tone).

In parallel with the above scales, their narrowed versions are used, so that the upper tone of the melody contour is performed a tone lower (fis-G-a, d-fis-G-a, d-esfis-G-a). Diatonic scales with the lowest tone serving as the referential pitch (G-a-h-cd), however typical of older Estonian folk song, are not characteristic of Setu songs. The difference from the Estonian runic tradition is evidently due to the polyphonic chorus tradition.

Table 10. Scales by the number of steps.

\begin{tabular}{|c|c|c|c|c|c|c|c|c|c|c|c|}
\hline $\begin{array}{l}\text { No. of } \\
\text { steps }\end{array}$ & & & \multicolumn{3}{|c|}{ Scale } & & & \multicolumn{2}{|c|}{$\begin{array}{l}\text { Chord Intervals } \\
\text { ambitus }\end{array}$} & $\begin{array}{l}\text { No.of } \\
\text { lines }\end{array}$ & $\%$ of lines \\
\hline 3.1 & & & fis & G & & bb & & $>4$ & $1-3$ & 188 & 35,1 \\
\hline 3.2 & d & & & G & & bb & & v. 6 & $5-3$ & 5 & 0,9 \\
\hline 3.3 & & & fis & G & a & & & v. 3 & $1-2$ & 40 & 7,5 \\
\hline 3.4 & & & & G & a & & & s. 3 & $2-2$ & 2 & 0,3 \\
\hline 4.1 & & & f fis & G & $\mathbf{a}$ & & & s. 3 & $1-1-2$ & 25 & 4,7 \\
\hline 4.2 & & & fis & G & a & bb & & $>4$ & $1-2-1$ & 19 & 3,4 \\
\hline 4.3 & & & fis & G & & bb & ces & $>5$ & $1-3-1$ & 1 & 0,1 \\
\hline 4.4 & d & & fis & G & & bb & & v. 6 & $4-1-1-3$ & 34 & 6,3 \\
\hline 4.5 & d & & fis & G & a & & & p. 5 & $4-1-2$ & 20 & 3,0 \\
\hline 4.6 & & es & fis & G & $\mathbf{a}$ & & & $>5$ & $3-1-2$ & 1 & 0,1 \\
\hline 5.1 & d & es & fis & G & $\mathbf{a}$ & & & p.5 & $1-3-1-2$ & 78 & 14,6 \\
\hline 5.2 & d & es & f & G & $\mathbf{a}$ & & & p. 5 & $1-2-2-2$ & 13 & 2,5 \\
\hline 5.3 & d & es & f fis & G & a & & & v. 6 & $1-2-1-1-2$ & 43 & 8,0 \\
\hline 5.4 & d & es & fis & G & & bb & & v. 6 & $1-3-1-3$ & 67 & 12,5 \\
\hline 5.5 & d & & fis & G & a & bb & & v. 6 & $4-1-2-1$ & 3 & 0,8 \\
\hline
\end{tabular}


The melodic structure of Setu bridal laments is closely bound to speech prosody. As in Estonian words stress always lies on the first (word-initial) syllable, the first syllable of a lament word is often sung higher than the following, unstressed syllable. This rule of language prosody is not observed in newer Setu tunes, that are not bound by the rules of spoken language. In laments, however, the role of text is very important, and so the stress is raised into prominence by means of a higher tone. Within a stress group the pitch usually moves downwards or stays level.

By ranking the initial tones of the stress groups it is possible to get an idea of the structure of lament melodies. The following table represents the melody patterns based on 2-5-step scales, covering more than half of the material analyzed. Exceptional to the prosodic rule are lament tunes with a lower tone in a stressed position of the ending formula (i.e. at the boundary of the third and fourth stress groups). Tunes based on 2-3step scales always have a falling contour which make them similar to laments for the dead, whereas tunes based on 4-5-tone scales have a rise-fall in they melodic contour, which brings them closer to lyro-epical songs.

Table 11. Melody contours schematized by stress-groups

\section{Stress groups}

\begin{tabular}{cllllll}
\multirow{5}{*}{ 2-chordal scales } & I & II & Trigger & III & Cadence IV \\
& & & & & & \\
& bb & bb & bb & G & & G \\
3-chordal scales & bb & bb & bb & bb & & G \\
& bb & bb & G & bb & & G \\
& bb & bb & bb & G- & fis & G \\
& bb & bb & bb & b-G & fis- & G \\
& bb & G & bb & G- & fis & G \\
& bb & G & G & bb-G & fis- & G \\
& bb & G & bb & bb-G & fis- & G \\
& bb-G & fis-bb & bb & G- & fis & G \\
& bb-G & fis-bb & bb & bb-G & fis- & G \\
& bb-G & fis & bb & G- & fis & G \\
4-chordal scales & a-G & fis & a & G- & fis & G \\
& d & bb & bb & G- & fis & G \\
& d & fis- & G & bb-G & fis- & G \\
& d & a & a & G- & fis & G \\
& d & fis- & fis & a-G & fis- & G \\
5-chordal scales & d-es & fis- & G & bb-G & fis- & G \\
& d-es & fis- & bb & G- & fis & G \\
& d-es & fis- & a & G- & fis & G
\end{tabular}

\section{Interactive structuring}

In the material analyzed, form, metre, rhythm, and melody are not equally regular. Most deviations occur in the melody. This made us look for a new method to analyze the lament tune proceeding from its own inherent regularities.

For the purpose of the present study the lament tune was addressed by an interactive structuring method. The characteristics of the metrical, rhythmic, and pitch 
structures of the bridal lament were fed into computer by melody lines numerically coded. The resulting data were analyzed by matrix calculus.

In the matrix every lament line is represented by 14 characteristics: 1 - number of the lament; 2 to 13 - the pitches of syllable notes; 14 - number of the line in the lament. If any of the positions between 2 and 13 is empty, it is marked with a zero. The + and signs are added to leading note "fis" to stress its belonging to the $3^{\text {rd }}$ stress group (+) or to the $4^{\text {th }}(-)$. An example can be found in Table 12 each of the 8 lines of which is a formal representation of a lament line, while every column represents the dynamics of a concrete feature (pitch used in a fixed position) throughout the 8-line lament.

Table 12. Matrix of the melodic contours of an 8-line bridal lament

\begin{tabular}{|c|c|c|c|c|c|}
\hline \multicolumn{2}{|c|}{$\begin{array}{l}\text { Number of } \\
\text { lament }\end{array}$} & \multicolumn{3}{|c|}{$\begin{array}{l}\text { The pitches of syllable notes } \\
\text { in stress-groups }\end{array}$} & \multirow{2}{*}{ 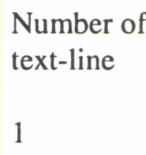 } \\
\hline 1 & fis $\mathrm{g} 0$ & a g a & $\mathrm{g} g+$ fis & g g & \\
\hline 1 & d es 0 & fis a a & $\mathrm{ag}$ & -fis $g \mathrm{~g}$ & 2 \\
\hline 1 & d es fis & a a a & g g & - fis $g \mathrm{~g}$ & 4 \\
\hline 1 & d es 0 & fis a a & a g & $-f i s \mathrm{~g} g$ & 7 \\
\hline 1 & d es 0 & fis $g a$ & $\mathrm{~g} g+\mathrm{fis}$ & g g & 3 \\
\hline 1 & d es 0 & fis $g$ a & $\mathrm{g} g+$ fis & g g & 5 \\
\hline 1 & $\mathrm{~d}$ es 0 & fis $\mathrm{g} a$ & $\mathrm{~g} g+\mathrm{fis}$ & $\mathrm{g} \mathrm{g}$ & 6 \\
\hline 1 & $\mathrm{~d}$ es 0 & fis $\mathrm{g} a$ & $\mathrm{~g}+\mathrm{fis}$ & $\mathrm{g} \mathrm{g}$ & 8 \\
\hline
\end{tabular}

The method was applied to the data recursively, so that at every round the most frequent subsets were separated. The results can be presented both in the form of a table and as a directed graph.

As mathematical analysis is a laborious process, the number of laments studied was confined to 20 ( 539 melodies in total, 14 positions in each). As a result the typical structural elements of the lament tunes were extracted, that largely coincide with empirical results (a stable ending formula, the frequent occurrence of a falling melody contour, consideration for word stress).

Beside the typical elements the analysis singled out hundreds of exceptions to the rules. Now the material was subjected to a second round of delimitation. This resulted in three songs by the best singers of Setumaa, which will next be discussed individually.

\section{Lament I}

A lament sung by Anne Vabarna (1877-1964), recorded at Tonja village in 1959 (Archives RKM, Mgn.II $325 \mathrm{~b}$ ). The lament is addressed to mother and it consists of 75 text lines. The lament expresses the bride's distress at her having to leave home too early, and her resignation to her lot. The singer comes from the northern part of Setumaa, where old songs had well survived into the early 20th century. She was a talented singer who had the traditional musical culture at her fingertips.

The lament tune is based on a three-step scale (at first 'fis-G-b', but since line 48 - 
evidently due to the fatigue beginning to show on the elderly singer - 'fis-G-a'). The main referential pitch is the middle step G, having mostly the function of the final tone of the melody.

Table 13. Scales of Anne Vabarna's lament

Intervallic composition $\quad$ No. of steps : 3 in semitones

$1-3$

$1-2$ fis

fis
G

G a
Chord-ambitus Number of text lines

60

15

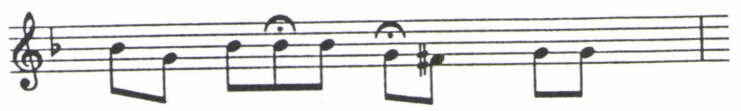

Note 1.

Throughout the performance the pitch contour of the lament retains the form of a descending curve. The actual pitches waver very little. The ending formula (fis-g-g), as well as its preceding step $(\mathrm{g})$ are absolutely stable. $84 \%$ of the lament is performed using the melody variant in which the first syllable-note (I.1) of the stress-group and the whole second stress-group (II.1,2,3) are sung on the highest pitch of the scale (b). Consequently, melodic variation concerns only two positions (I.2 and III.1) of the metric pattern.

I.2 is an unstressed position filled either by the second syllable of a two-syllable word or the unstressed syllable of the first half of a four-syllable word ('näi-o; ' maa$\left.m a-\left[{ }^{\prime} k \tilde{o}-n \tilde{o}\right]\right)$. According to Estonian prosody an unstressed syllable should sound either lower than the preceding stressed syllable or at least on the same level with it. This rule is observed in the lament sung by Anne Vabarna. Evidently the singer uses the two melodic variants intentionally to make a difference in the content plane: in the beginning of the lament, when emotional tension has not yet culminated and the story dominates, the falling curve (b-g) is used as is more characteristic of speech, whereas towards the end when lamenting is beginning to affect one's emotions even outside the ritual situation, the level tune (b-b) predominates, raising the tension until the fall and resolution are brought by the ending formula.

The position III. 1 of the metric pattern is a stressed position: the beginning of a new word coincides with that of a new half-line. This is why here the singer in most cases prefers the higher pitch, so that the fall (b-g) could make the word stress more salient. The few cases in which the position III.1 is filled by a lower tone (g) seem to be motivated by text peculiarities: both the third and fourth stress groups are either filled by a two-syllable word (ol-gõ nõa-lõ) or by the respective halves of a foursyllable word $(a r-m a-k \tilde{o}-n \tilde{o})$ which means that the regular $2+3$ or $3+2$ pattern is violated. The singer's reaction is to prolong the first syllable of the second half-line so 
that the regular rhythm of the second half-line is restored at the expense of the lengthened third stress-group $(3+2)$. Here the prolonged syllable is always sung on a lower pitch (g-g-fis g-g).

Although the scale composition changes towards the end of the lament, the general contour of the tune is retained. The lines performed with the upper step lowered by a semitone (levels 1.2.1 and 1.3.1) are just lower variants of the melodies previously used.

Table 14. The melodic contours occurring in Anne Vabarna's lament

\begin{tabular}{|c|c|c|c|c|c|c|c|}
\hline $\begin{array}{l}\text { Stress } \\
\text { Levels }\end{array}$ & oups & I & II & III & IV & $\begin{array}{r}\text { Proportional / } \\
\text { absolu }\end{array}$ & number \\
\hline I-VIII & 1.1.1.1.1 & bb-G & bb-bb-bb & bb-G & fis- $G-G$ & 0,500 & 120 \\
\hline & 1.1.1.1.2 & bb-bb & bb-bb-bb & bb-G & fis- G-G & 0,500 & $/ 20$ \\
\hline & 1.1.1.2.1 & bb-bb & bb-bb-bb & bb-G- & fis $G-G$ & 0,259 & 17 \\
\hline & 1.1.1.3.1 & bb-G & bb-bb-bb & bb-G- & G-G & 0,231 & 16 \\
\hline & 1.1.2.1.1 & bb-G & bb-bb-bb & G-G- & fis $\quad G-G$ & 0,538 & 17 \\
\hline & 1.1.3.1.1 & bbb-bb & bb-bb-bb & G-G- & fis $\quad G-G$ & 0,300 & 13 \\
\hline & 1.2 .1 & $\mathrm{a}-\mathrm{a}$ & $a-a-a$ & $\mathrm{a}-\mathrm{G}$ & fis- $G-G$ & 0,200 & $/ 10$ \\
\hline & 1.3 .1 & $a-a$ & $a-a-a$ & a-G- & fis $\quad G-G$ & 0,080 & 12 \\
\hline
\end{tabular}

\section{Lament II}

A lament sung by Helena Laanetu (1909-1997), recorded at Suure-Rõsna village in 1971 (Archives RKM, Mgn.II 2095 b). The lament consists of 33 text lines, being addressed to the bride's brother. First the girl describes their destination - the farm of the relatives to whom they are going to take the wedding invitation. Second, she asks her brother to guide the horse carefully, to prevent an accident from happening in the forest. The singer was a neighbour of Anne Vabarna and she was well familiar with the local tradition. But she was a generation younger than Anne and meanwhile the traditional lifestyle had receded, moving the style of laments closer to that of a song.

The bridal lament is based on a five-step scale (occasionally a four-step one with a void) that is typical of lyro-epic songs. The main referential pitch ' $G$ ' occupies the middle position. The upper tetrachord is represented by a third tone located three semitones higher, while the lower tetrachord always has a subquart (d), often complemented by a subthird (es).

Table 15. Scales of Helena Laanetu's lament

Intervallic composition No. of steps: 4-5 in semitones

Chord-ambitus Number of text lines

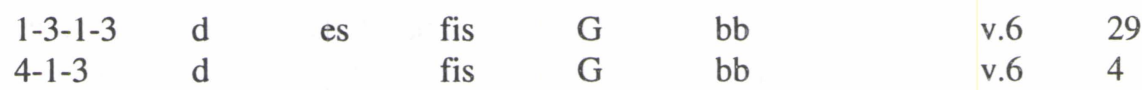




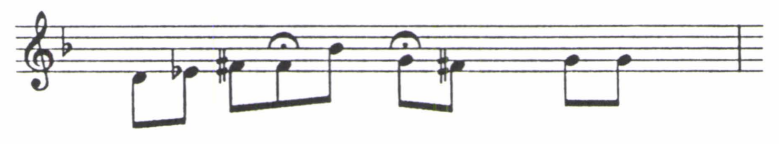

Note 2.

The melody contour has acquired the wavy form of a rise-fall. The rules of variation are clear: throughout the lament the cadence as well as the initial tone are stable, as well as the culminating tone ' $b$ ' in the beginning of the third stress group. Variants of the tune differ in unstressed positions (I.2, II.2,3). The position I.2, usually fulfilled by the step 'es' that is higher than the stressed tone, is stable on $85 \%$ of cases. This is a clear proof of the predomination of rules of musical composition here, as the intense melody contour (d-es-fis) is held more important than the falling prosodic contour of the text. In four cases, however, the pitch of I.2 remains level. As far as the motif 'd-d' of the first stress-group stands in a close correlation with the position III.1, it is used for the highest step ' $b$ ' of the scale, while the lax beginning is compensated by a diminished fourth 'fis-bb'. Another position in close correlation with III.1 is II.3. If the former has the highest step ' $b$ ', it is usually preceded by 'fis', sometimes by ' $b$ '. In the latter case, if the maximum pitch has been used in stress group II, the beginning of stress group III may also begin on a lower step ' $\mathrm{g}$ '.

Table 16. The melodic contours occurring in Helena Laanetu's lament

$\begin{array}{lllllllll}\begin{array}{l}\text { Stress groups } \\ \text { Levels I-VII }\end{array} & \text { I } & \text { II } & \text { III } & \text { IV } & & \text { Proportional / } \\ & & & & & & & & \\ \text { absolute } \\ \text { number }\end{array}$

\section{Lament III}

Maarja Pähnapuu's (b. 1914) lament, Kosselka village (Archives RKM, Mgn. 3190 (6)). The lament, addressed to a village lad, contains 15 text lines. The bride asks why the young man did not woo her, although she had been waiting for him. Supposedly he was afraid of the girl getting too little dowry.

The lamenter comes from the southern part of Setumaa, where Setu villages stand side by side with Russian ones. Being one of the best Setu singers of today, Maarja Pähnapuu can improvise on any situation conceivable. But she is the youngest of all lamenters and lives isolated from the main Setu population. 
The lament tune is characterized by considerable variation: the 15 text lines are sung on 9 melodic variants, which makes the variance $60 \%$. The scale is changed repeatedly as well.

Table 17. Scales of Maarja Pähnapuu's lament

Intervallic composition in No. of steps:3-4-5 semitones
Chordal Number ambitus of text line

\begin{tabular}{|c|c|c|c|c|c|c|}
\hline $1-3$ & & fis & G & & bb & $>4$ \\
\hline $4-1-3$ & d & fis & G & & bb & v. 6 \\
\hline $3-1-2$ & es & fis & G & a & & $<4$ \\
\hline $1-3-1-2$ & $\mathrm{~d}$ es & fis & G & a & & p. 5 \\
\hline $4-1-2$ & d & fis & G & $\mathrm{a}$ & & p. 5 \\
\hline
\end{tabular}

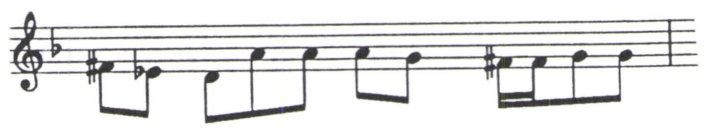

Note 3.

The least typical element of the lament is the melodic contour that keeps changing all the time. The falling (Vabarna's kind) and rising-falling (Laanetu's kind) melodies are missing altogether. Predominantly the melody consists of two-wave contours containing large intervallic leaps. This leads one to guess that the singer is not familiar with the rules to compose a lament tune, or has forgotten them. The only formula remaining stable is the end formula, here starts the chorus following the leadsinger's part. Positions I.2 and II.1 are also quite stable, they constitute the middle part of the first descending curve (bb-g-fis; a-g-fis). The first curve may also be ascending (d-es-fis; $d$ $d-b b)$. The highest pitch $(b b ; a)$ is situated et the beginning of the first and the third stress groups, and therefore the beginnings of half-lines correspond to the rules of speech melody. Also in this lament melody, the end of the first half-line is the one filled most freely.

Table 18. The melodic contours occurring in Maarja Pähnapuu's lament

\begin{tabular}{|c|c|c|c|c|c|c|c|}
\hline $\begin{array}{l}\text { Stress } \\
\text { Level }\end{array}$ & $\begin{array}{l}\text { groups } \\
\text { s }\end{array}$ & I & II & III & IV & Propo & $\begin{array}{l}\text { tional/ } \\
\text { absolute number }\end{array}$ \\
\hline I-IX & 1.1.1.1.1.1.1 & bb-G & fis-bb-bb & bb-G & fis- & G-G & $0,833 \quad 15$ \\
\hline & 1.1.1.1.1.1.2 & bb-G & fis-bb-bb & bb-G- & fis & G-G & $0,167 / 1$ \\
\hline & 1.1.1.1.1.2.1 & bb-G & fis-bb-bb & G-G- & fis & G-G & $0,500 / 1$ \\
\hline & 1.1.1.1.2.1 & $a-G$ & fis-d-a & $a-G$ & fis- & G-G & $0,286 / 2$ \\
\hline & 1.1.1.1.3.1 & $\mathrm{a}-\mathrm{G}$ & fis-es-a & a-G- & fis & G-G & $0,333 / 1$ \\
\hline & 1.1.1.2.1.1 & d-es & fis-a-fis & $a-G$ & fis- & G-G & $0,500 / 2$ \\
\hline & 1.1.2.2.1.2 & fis-es & $d-a-a$ & $a-G$ & fis- & G-G & $0,333 / 1$ \\
\hline & 1.1.3.1.1.1 & $d-d$ & bb-bb-G & bb-G- & fis & G-G & $0,500 / 1$ \\
\hline & 1.2.1.1.1.1 & $a-G$ & fis-d-d & d-d- & fis- & G-G & $0,333 / 1$ \\
\hline
\end{tabular}




\section{Conclusion}

A Setu lament tune consists of four melody segments, the length of each corresponding to the length of one stress group. Each melody segment consists of 2-3 syllable-notes. Of those segments the falling (b-g, b-g-fis, a-g, a-g-fis, g-g-fis) and the level kinds (71\% of the whole material) are in harmony with the rules of Estonian speech prosody ${ }^{2}$. Fragments in a cadence are rising if they contain 3 syllable-pitches (fis-g-g). A rising fragment with the stressed tone sung lower than the following ones is at variance with the rules of speech prosody. It occurs only in the first half-line. (It never occurs in Vabarna's lament, while Laanetu has 'd-es' and 'fis-b' and Pähnapuu has 'fis-b', 'd-a', 'es-a', 'd-es', and 'fis-a').

Table 19. Types of pitch movement as measured in the stress groups of three laments; the percentage, number and sum total $(\Sigma)$ of the respective stress groups

\begin{tabular}{llllll} 
Lament (singer) & Fall $\searrow$ & Level $\rightarrow$ & Cadence $\lambda$ Rise $\rtimes$ & \\
I (Vabarna) & $36 \%(108)$ & $47 \%(142)$ & $17 \%(50)$ & 0 & $\sum 300$ \\
II (Laanetu) & $19 \%(25)$ & $29 \%(38)$ & $23 \%(30)$ & $30 \%(39)$ & $\sum 132$ \\
III (Pähnapuu) & $47 \%(28)$ & $10 \%(6)$ & $18 \%(11)$ & $25 \%(15)$ & $\sum 60$ \\
\hline Total & $33 \%(161)$ & $38 \%(186)$ & $18 \%(91)$ & $11 \%(54)$ & $\Sigma 492$
\end{tabular}

The melody style of a Setu lament seems to bee manifested in a regular pitch structure in consistent use, while stability in scales and melody contours does not mean their exact repetition throughout the lament, but rather a varied performance of the melody.

Despite of similar scales, the styles of three commendable Setu singers are different enough. While creating the melody each has made her own choices, which points to differences in musical thinking observable within one and the same genre of folk song.

1. Anne Vabarna's performance with its stable scale, falling melody contours and a small proportion (10\%) of melodic variants could be classified as 'lament-like'. 2. Helena Laanetu's style with its continuously rising and falling melody contour (though the set of scales alternates) and a relatively small proportion (20\%) of melodic variants could be characterized as 'song-like'.

3. As for Maarja Pähnapuu's performance, it can hardly be called traditionally stylish, as constant variation applies not only to the melody contour but also to the underlying scale. The fact that the proportion of variance (60\%) surpasses that of the stable fragments seems to indicate that the singer is either not familiar with the traditional rules of melody composition or has, for some reason or other, forgotten how to use them. On the other hand, her performance gives a good example of the

\footnotetext{
${ }^{2}$ The prosodic (or suprasegmental) structure of a language contains stress, duration and tone play in the production of words, determing their lexical meaning (Ilse Lehiste, The phonetics of metrics. - Empirical studies of the arts, Vol. 10(2): 95-120,1992.) In Estonian stress is fixed on the first syllable of a word and it includes a higher pitch.
} 
Setu wedding lament being adjusted to contemporary music.

Our analysis of the Setu lament tune by means of interactive structuring has proved that the style of the melodies of bridal laments depends on the status of the lamenting culture in a certain region at a certain period. In northern Setumaa, where the older tradition survived longer, the pitch structure of laments is clearer and the rules of lament performance are observed more strictly. In southern Setumaa, however, where the tradition of lament weddings ended sooner and the decline of the traditional Setu society proceeded more rapidly, the melodies of bridal laments are defined less clearly.

Another important indicator is the singer's year of birth: the earlier the year of birth, the more determinate the lament melody. The underlying rules of a lament tune have changed during the economic and social transformations that put an end to the traditional wedding. The shrinking opportunities for the performance of traditional music meant less chance for learning its rules.

To a certain extent the melodic composition of a lament is also dependent on the personality of the singer as well as on the addressee of the lament. Emotional singers have provided appeasing laments with more dramatic features that, beside text elements, show in an excited rhythm and a saltatory melodic contour. If the addressee has caused the lamenter to grieve, the lament is used to analyze its possible reasons and it may well happen that emotions get the better of a generally steady lamenting process.

A comparison of the pitch structures of the three selected laments with those of the rest of the lament tunes has shown that the favourite melody contour used in this material has 4-5 steps producing a song-like rise-fall within a flat sixth. The falling contour of 2-3 steps with the chord-ambitus of a flat fourth, that seems to have dominated earlier, had remained in the minority by the time the laments were recorded. Lament tunes belonging to neither of the two styles are met rarely indeed. It seems that Setu laments, representing a pre-Christian world view, have tolerated no more than just one change of style, the one likening them to songs, but now they are definitely on their way out, together with the ongoing rapid loss of the live lamenting tradition once so characteristic of Setumaa.

\section{References}

Lippus, Urve 1995. Linear Musical Thinking. Studia Musicologica Universitatis Helsingiensis VII.

Pärtlas, Zhanna 1997. Tähelepanekuid setu laulu laadiehitusest ja mitmehäälsusest. Teater, Muusika, Kino 1, 23-28.

Põldmäe, Jaak, Eesti värsiõpetus. Tallinn, 1978: 154.

Sarv, Vaike 1986. Vvidõ setuskih pritchitanii i ih muzõkalnõe osobennosti. - Muzõka

v obrjadah I trudovoi dejatelnosti finno-ugrov. Tallinn, Eesti Raamat, 188-215.

Sarv, Vaike 1993. Setu itkuvärsi meetrikast. - Keel ja Kirjandus 5, 282-292. 